\title{
1-Chloro-1,3-butadiene Copolymers VI. Structure of the Diene Unit and Monomer Sequence Distribution in the Copolymer with Styrene
}

\author{
Shinzo KOHJIYA, Yoshihiko ImOTo, and Shinzo YAMASHITA \\ Department of Chemistry, Kyoto Institute of Technology, \\ Matsugasaki, Kyoto 606, Japan
}

(Received July 17, 1985)

\begin{abstract}
Microstructures in the copolymer of 1-chloro-1,3-butadiene (CB) and styrene (St) obtained by radical polymerization in bulk were investigated by spectroscopic methods. The microstructure of CB units in the copolymer was found as follows: $60 \% 1,4$ and $40 \% 3,4$ structures by ${ }^{1} \mathrm{H}$ NMR; ca. $50 \%$ trans- 1,4 , ca. $5 \%$ cis-1,4, and ca. 45\% 3,4 structures by IR. About $60 \%$ chlorine in the 1,4 CB unit was estimated to be very reactive because it is an allylic chlorine. After hydrogen chloride elimination from poly(CB-co-St), diad(1,4 CB-1,4 CB) and triad(1,4 CB-1,4 CB$1,4 \mathrm{CB}$ ) were determined by UV-visible spectroscopy. The results were in accord with the theoretical ones calculated from the monomer reactivity ratios derived from the terminal model (simple Markov) and the feed composition; the distribution of 1,4 and 3,4 structures was assumed completely random (Bernoullian).
\end{abstract}

KEY WORDS Microstructure / Monomer Sequence Distribution $/{ }^{1} \mathrm{H}$ NMR / IR Spectroscopy / 1-Chloro-1,3-butadiene / Styrene / Copolymer /

Thin-layer chromatographic study ${ }^{1}$ of the copolymer of 1-chloro-1,3-butadiene (CB) and styrene $(\mathrm{St})$ has shown that the monomer reactivity ratios $^{2}$ based on the terminal model can explain the composition and distribution of poly(CB-co-St). The monomer sequence distribution can also be calculated from monomer reactivity ratios. The validity of the copolymerization kinetics can best be examined by the observation of sequence distribution in the copolymers. However, there are few cases which permit a direct analysis of sequence distribution.

Winston and Wichacheewa ${ }^{3}$ studied. sequence distribution in poly(CB-co-St) obtained by radiation-induced polymerization in bulk. They assumed that all the CB units in the copolymer were in the 1,4 configuration without any detailed spectroscopic studies on the structure of CB units. Our experimental results are difficult to reconcile with their observa- tions; i.e., the degrees of the reactions of chlorine in poly(CB-co-1,3-butadiene) with amine ${ }^{4}$ sodium diethyldithiocarbamate ${ }^{5}$ or water (hydrolysis) ${ }^{6}$ had a limiting value at $c a$. $60 \%$, and ${ }^{1} \mathrm{H}$ NMR of poly(CB-co-St) obtained by solution polymerization ${ }^{7}$ showed the presence of $c a .60 \%$ in the 1,4 structure and the rest in the 3,4 configuration. Since the chlorine in the 1,4 structure is allylic and is very reactive in nucleophilic substitution reaction, ${ }^{8}$ these result could be fully understood by the presence of $c a .60 \% 1,4$ structure and $c a .40 \% 3,4$ structure in both poly(CB-co-St) and poly(CBco-1,3-butadiene).

In this paper, the microstructure of $\mathrm{CB}$ units in poly(CB-co-St) is established by both ${ }^{1} \mathrm{H}$ NMR and IR spectroscopies, and the monomer sequence distribution in poly(CB-co-St) is reinvestigated, taking the microstructure of CB units into account. 


\section{EXPERIMENTAL}

\section{Materials}

$\mathrm{CB}$ and poly(CB-co-St) were synthesized according to the reported methods. ${ }^{1,2,7}$ As low molecular-weight model compounds for spectroscopic studies of the structure of $\mathrm{CB}$ units, four compounds were used: (1) the model for the 1,2 structure, i.e., 4-chloro-1-butene, was synthesized by the reported method, ${ }^{9}$ and the purity by GPLC was $98.1 \%$; (2) the model for the cis-1,4 structure, i.e., cis-1-chloro-2-butene, was synthesized, ${ }^{10}$ and the purity by GPLC was $99.7 \%$; (3) the model for the trans1,4 structure, i.e., trans-1-chloro-2-butene, was commercially available and purified by repeated distillations (bp $84.0^{\circ} \mathrm{C}$, lit. ${ }^{10} 84.8^{\circ} \mathrm{C}$ ). The purity was $99.5 \%$ by GLPC; (4) the model for the 3,4 structure, i.e., 1-chloro-1-butene, was synthesized, ${ }^{11}$ and the trans/cis ratio was 2.22 by GLPC. All other reagents were commercially available and purified by standard methods.

\section{Polymer Characterization}

Membrane osmometry, gel-permeation chromatography, and elemental analysis were described in the preceding papers. ${ }^{1,2}$ IR spectra of carbon tetrachloride solutions and ${ }^{1} \mathrm{H}$ NMR spectra were measured on a Hitachi IR Spectrophotometer 215 and a Varian T-60A, respectively. UV spectra were recorded using a Toshiba-Beckman DB-G Grating Spectrophotometer. The elimination reaction of hydrogen chloride from poly(CB-co-St) was conducted according to the reported method. ${ }^{3}$

\section{RESULTS AND DISCUSSION}

\section{Microstructure of $C B$ units by ${ }^{1} H N M R$}

In one of our earlier papers of this series, ${ }^{7}$ we reported the microstructure of $\mathrm{CB}$ units in poly(CB-co-St) obtained by solution polymerization with AIBN. The copolymers of CB and St obtained by bulk polymerization ${ }^{1,2}$ were subjected to ${ }^{1} \mathrm{H}$ NMR measurement. They showed exactly the same features in their ${ }^{1} \mathrm{H}$ NMR spectra (see Figure 1) as those by solution polymerization. ${ }^{7}$ Again, the 1,2 structure was not detected because there is no peak at the $c a$. $5.0 \mathrm{ppm}$ region (terminal vinyl protons). ${ }^{7}$ Comparing the spectra $\mathrm{A}$ and $\mathrm{B}$, one could estimate the presence of the 1,4 structure. The spectrum of trans-1-chloro-2-butene is shown in Figure 1 (B). The spectrum of the cis isomer was essentially the same as that of the trans isomer. A peak ascribable to the 3,4 structure should be mentioned, since Winston and Wichacheewa ${ }^{3}$ failed to observe it. It was observed at $\delta=5.8-6.2 \mathrm{ppm}$ in the spectra of poly(CB-co-St)s and at $\delta=5.8-6.1 \mathrm{ppm}$ in the spectrum of 1-chloro-1-butene (the spectrum $\mathrm{C}$ in Figure 1) used as a model compound for the 3,4 structure. It can be assigned to olefinic protons geminal and vicinal to the chlorine in 1-chloro-1-butene or the 3,4-structural CB unit. It was always observed clearly regardless of the copolymer composition and indicates the presence of the 3,4 structure against the claim of Winston and Wichacheewa. ${ }^{3}$ This discrepancy is difficult to explain because both polymers were synthesized by radical polymerization in bulk. Adopting the reported assignment, ${ }^{7}$ we evaluated the structure of $\mathrm{CB}$ units in the polymers. The results are shown in Table I. As the CB content increases, the 1,4structure content remains constant within the experimental error of ${ }^{1} \mathrm{H}$ NMR measurement, and the average value of 1,4-structure content $(58 \pm 3 \%)$ is in good agreement with the reported constant value $(59 \pm 5 \%)$ for poly (CB$\mathrm{co}$-St)s obtained by solution polymerization. ${ }^{7}$ In spite of the presence of phenyl groups of $\mathrm{St}$ units, their effect on the chemical shifts was not observed in the present experiment.

\section{Microstructure of $C B$ Units by IR}

By ${ }^{1} \mathrm{H}$ NMR, we could determine 1,4 and 3,4 structures, but cis and trans structures were not distinguishable. This geometrical isomerism is possible for both 1,4 and 3,4 structures, but the isomerism in the 3,4 structure may not 


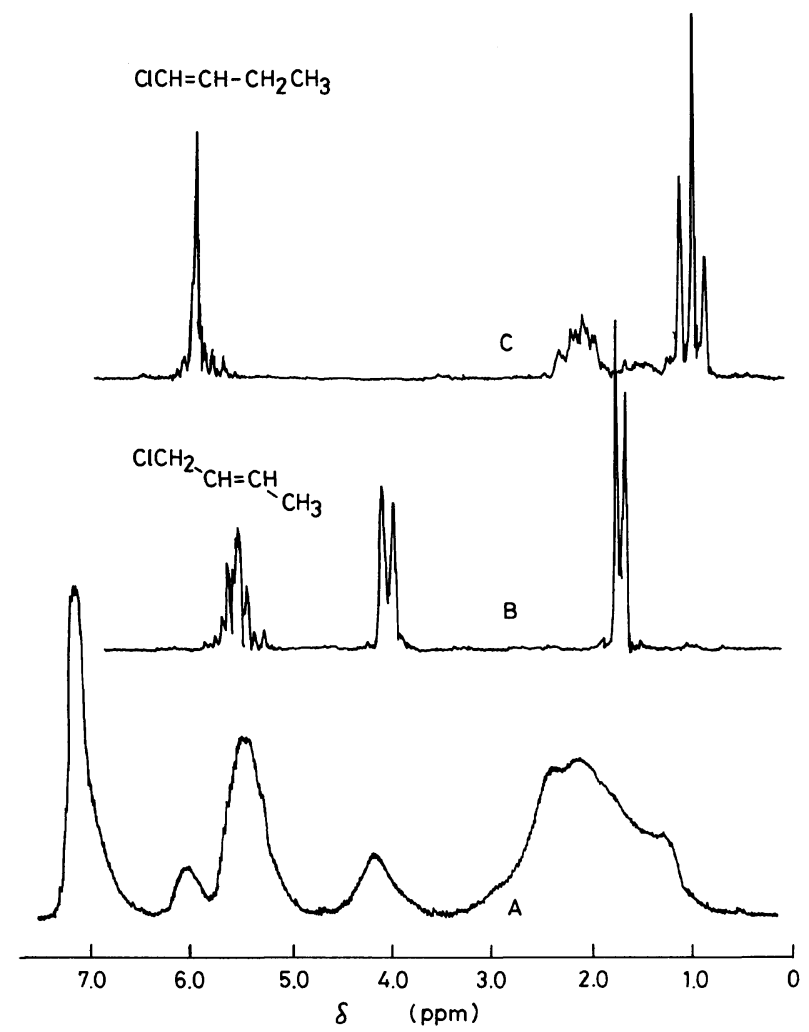

Figure 1. ${ }^{1} \mathrm{H}$ NMR spectra $\left(\mathrm{CDCl}_{3}, 60 \mathrm{MHz}\right)$ : (A), poly(CB-co-St) No. 3 in Table I; (B), trans-1-chloro2-butene, the model for the trans-1,4 structure; (C), 1-chloro-1-butene, the model for the 3,4 structure.

Table I. Structure of CB unit by ${ }^{1} \mathrm{H}$ NMR

\begin{tabular}{|c|c|c|c|}
\hline \multirow{2}{*}{ No. } & \multirow{2}{*}{$\begin{array}{c}\begin{array}{c}\mathrm{CB} \text { content in } \\
\text { copolymer }\end{array} \\
\mathrm{mol} \%\end{array}$} & \multicolumn{2}{|c|}{$\begin{array}{l}\text { Structure of the CB unit/ } \\
\mathrm{mol} \%\end{array}$} \\
\hline & & 1,4 & 3,4 \\
\hline 1 & 12.8 & 62 & 38 \\
\hline 2 & 24.4 & 59 & 41 \\
\hline 3 & 35.4 & 61 & 39 \\
\hline 4 & 46.5 & 55 & 45 \\
\hline 5 & 55.7 & 56 & 44 \\
\hline 6 & 67.5 & 59 & 41 \\
\hline 7 & 77.0 & 56 & 44 \\
\hline 8 & 85.9 & 56 & 44 \\
\hline 9 & 90.9 & 57 & 43 \\
\hline 10 & 100 & 56 & 44 \\
\hline
\end{tabular}

be important because the double-bond unit is not on the main chain of the polymers. Using the four model compounds, we studied the IR spectra of poly(CB-co-St)s. An example of the
IR spectra is shown in Figure 2, and structures and key absorptions in IR are presented in Table II. In the IR spectra of CB-St copolymers, all the key bands of cis and trans-1,4 and 3,4 structures were observed, but those of the 1,2 structure were not. Unfortunately, the $769 \mathrm{~cm}^{-1}$ band of $c i s-1,4$ could not be used for quantification owing to overlapping with the $750 \mathrm{~cm}^{-1}$ band of polystyrene. We had to use three carbon-carbon stretching bands at $1680-1630 \mathrm{~cm}^{-1}$ for the analysis. The absorption coefficients of these bands were determined from IR spectra of the corresponding model compounds, which are listed in Table III.

Three absorbances at 1675, 1660, and 1635 $\mathrm{cm}^{-1}$ are expressed as follows:

$$
\frac{A_{1675}}{d}=\varepsilon_{c i s}^{1675} C_{\text {cis }}+\varepsilon_{\text {trans }}^{1675} C_{\text {trans }}+\varepsilon_{3,4}^{1675} C_{3,4}
$$




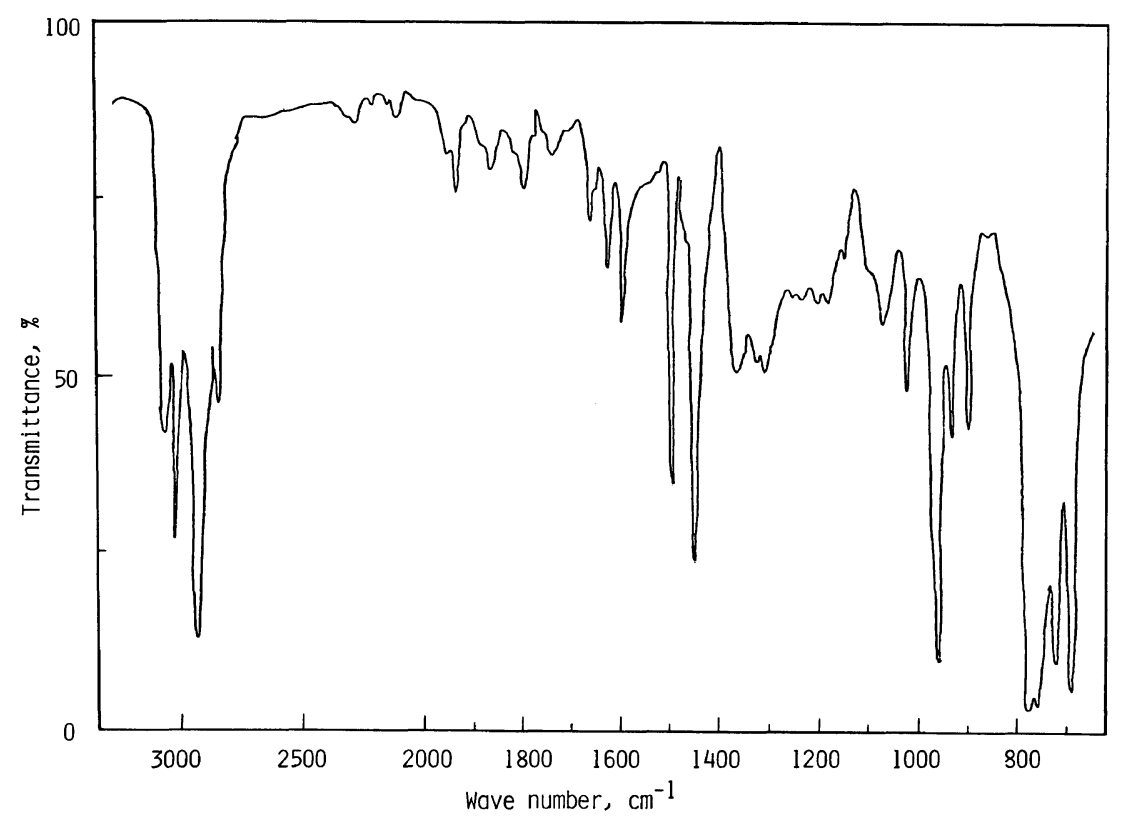

Figure 2. IR spectrum of $\mathrm{P}(\mathrm{CB}-\mathrm{co}-\mathrm{St})$ : $\mathrm{CB}$ content, $55.7 \mathrm{~mol} \%$ (No. 5 in Table I).

Table II. Structure and key IR band of the CB unit

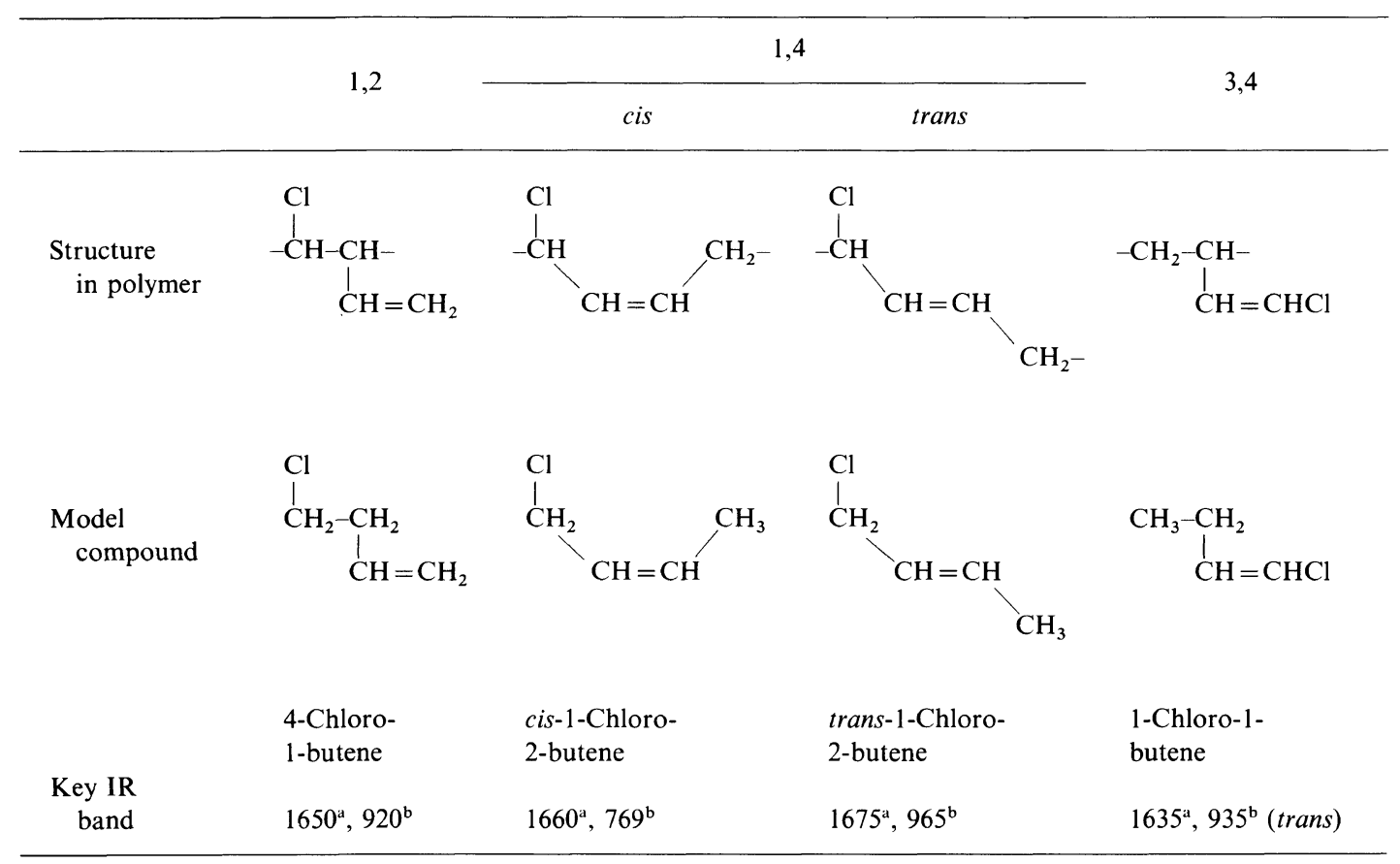

a Stretching of $\mathrm{C}=\mathrm{C}$.

b Out-of-plane deformation of $=\mathrm{C}-\mathrm{H}$. 
Table III. Absorption coefficients $\left(1 \mathrm{~g}^{-1} \mathrm{~cm}^{-1}\right)$ from model compounds ${ }^{a}$

\begin{tabular}{cccc}
\hline $\mathrm{cm}^{-1}$ & cis-1,4 & trans-1,4 & 3,4 \\
\hline 1675 & $0.002_{2}$ & $0.174_{5}$ & $0.007_{7}$ \\
1660 & $0.098_{5}$ & $0.038_{8}$ & $0.050_{1}$ \\
1635 & $0.005_{2}$ & 0 & $0.284_{1}$ \\
\hline
\end{tabular}

a Measured in carbon tetrachloride solution interposed between potassium bromide plates in a fixed cell of $0.50 \mathrm{~mm}$ thickness. The concentration was $10.0 \mathrm{~g}^{-1}$.

Table IV. Structure of CB unit by IR

\begin{tabular}{rccccc}
\hline & \multicolumn{2}{c}{$\begin{array}{c}\text { CB content in } \\
\text { copolymer }\end{array}$} & & \multicolumn{3}{c}{$\begin{array}{c}\text { Structure of the CB unit } \\
\text { mol } \%\end{array}$} \\
\cline { 2 - 2 } \cline { 4 - 6 } & mol $\%$ & & cis 1,4 & trans 1,4 & 3,4 \\
\hline 5 & 55.7 & & 6 & 50 & 43 \\
6 & 67.5 & & 6 & 49 & 44 \\
7 & 77.0 & & 6 & 48 & 46 \\
8 & 85.9 & & 1 & 50 & 49 \\
9 & 90.9 & 5 & 47 & 48 \\
10 & 100 & 5 & 47 & 47 \\
\hline
\end{tabular}

a The totals are very near to $100 \%$, but somewhat less than $100 \%$ in some cases, possibly owing to the use of absorption coefficients for low molecular weight model compounds.

$$
\begin{aligned}
& \frac{A_{1660}}{d}=\varepsilon_{c i s}^{1660} C_{c i s}+\varepsilon_{\text {trans }}^{1660} C_{\text {trans }}+\varepsilon_{3,4}^{1660} C_{3,4} \\
& \frac{A_{1635}}{d}=\varepsilon_{\text {cis }}^{1635} C_{\text {cis }}+\varepsilon_{\text {trans }}^{1635} C_{\text {trans }}+\varepsilon_{3,4}^{1635} C_{3,4}
\end{aligned}
$$

where $A_{1675}$ is the absorbance at $1675 \mathrm{~cm}^{-1}, d$, the thickness of a sample solution, $\varepsilon_{c i s}^{1675}$, the absorption coefficient of cis-1,4 structure at $1675 \mathrm{~cm}^{-1}$ shown in Table III, $C_{c i s}$, the concentration $\left(\mathrm{g}^{-1}\right)$ of cis-1,4 structure and so on. Using the values in Table III and solving eq $1-3$ at $d=0.05 \mathrm{~cm}$, we obtained the values for $C_{c i s}, C_{\text {trans }}$, and $C_{3,4}$. Table IV shows the results and the structure of $\mathrm{CB}$ units in poly(CB-co-St) was found as follows: $c i s-1,4, c a$. $5 \%$; trans $-1,4$, ca. $50 \%$; 3,4 structure, ca. $45 \%$. Considering the magnitude and proximity of the three key bands, the results in Table IV are less certain but in reasonable agreement with those in Table I. Several studies on poly- mers from 1-substituted-1,3-butadiene by radical polymerizations have been published so far, ${ }^{3,12-16}$ but the present study is the first one that estimated the microstructure of diene units by both NMR and IR techniques. All of them reported that major structure in the 1substituted-1,3-butadiene unit was trans-1,4 which is in accord with the present study.

\section{Monomer Sequence Distribution}

The physical properties of a copolymer are much influenced by the monomer sequence distribution. Furthermore, information on sequence distribution provides the best method to check the validity of coolymerization $\mathrm{ki}$ netics from which the monomer reactivity ratios are derived. Winston and Wichacheewa ${ }^{3}$ observed the sequence distribution in poly(CBco-St) from the UV spectra of conjugated polyenes produced in the copolymer after hydrogen chloride elimination. However, though not actually so, they assumed that all CB units were in the 1,4 configuration; i.e., all the chlorine would have been eliminated, and their treatment of spectral data based on the assumption that all polyenes had an identical absorption coefficient, which is contrary to available data. ${ }^{17}$

Therefore we reinvestigated the monomer sequence distribution in poly(CB-co-St). Hydrogen chloride elimination was carried out in dimethylformamide $(100 \mathrm{mg}$ polymer in $100 \mathrm{ml}$ solvent) at $160^{\circ} \mathrm{C}$ using $10 \mathrm{mg}$ triethylamine as the $\mathrm{HCl}$ acceptor. ${ }^{3}$ Figure 3 shows the UV spectrum of no. 11 after the elimination reaction, which is essentially identical with the reported one. ${ }^{3}$ Figure 4 shows the time course of the reaction. In $40 \mathrm{~min}$, the reaction proceeded to give a constant absorbance, and when the copolymer contained a large amount of CB (No. 12), the absorbance declined after around $80 \mathrm{~min}$. Some complicated reactions might have occurred by the evolved hydrogen chloride. We estimated that all the reactive chlorine on 1,4 CB units was eliminated after 60 min. $^{4,5,8}$ 


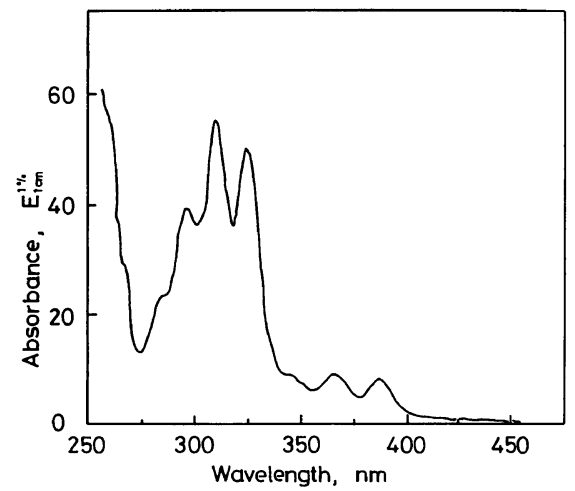

Figure 3. UV spectrum of poly $(\mathrm{CB}-c o-\mathrm{St})$ in $\mathrm{DMF}$ after hydrogen chloride elimination, the reaction solution was diluted to one tenth (No. 11 in Table V).

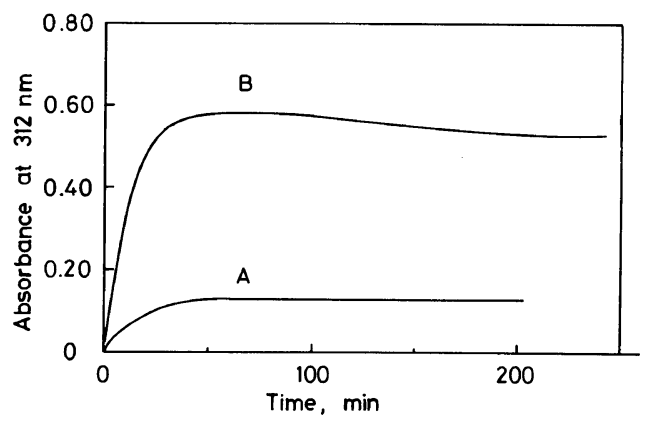

Figure 4. Variation of absorbance at $312 \mathrm{~nm}$ of poly (CB-co-St) treated with triethylamine at $160^{\circ} \mathrm{C}$ in DMF: (A), poly(CB-co-St) No. 11; (B), poly(CB-co-St) No. 12 (see Table V).

Monomer sequence distribution has been calculated from monomer reactivity ratios and the feed composition. ${ }^{18}$ When the simple Markov treatment or the terminal model is applicable, the Mayo-Lewis equation holds and diad, triad and tetrad are expressed as follows:

$$
\begin{aligned}
P_{2}\left(\mathrm{M}_{1} \mathrm{M}_{1}\right) & =\frac{1+r_{1} x}{r_{1} x+2+r_{2} / x} \cdot \frac{r_{1} x}{1+r_{1} x} \\
P_{3}\left(\mathrm{M}_{1} \mathrm{M}_{1} \mathrm{M}_{1}\right) & =\frac{1+r_{1} x}{r_{1} x+2+r_{2} / x} \cdot\left(\frac{r_{1} x}{1+r_{1} x}\right)^{2}
\end{aligned}
$$

$P_{4}\left(\mathrm{M}_{1} \mathrm{M}_{1} \mathrm{M}_{1} \mathrm{M}_{1}\right)=\frac{1+r_{1} x}{r_{1} x+2+r_{2} / x} \cdot\left(\frac{r_{1} x}{1+r_{1} x}\right)^{3}$ where $r_{1}$ and $r_{2}$ are monomer reactivity ratios, $x=\mathrm{M}_{1} / \mathrm{M}_{2}, P_{2}\left(\mathrm{M}_{1} \mathrm{M}_{1}\right)$ is the probability of finding the $\mathbf{M}_{1} \mathbf{M}_{1}$ diad in a polymer chain, $P_{3}\left(\mathrm{M}_{1} \mathrm{M}_{1} \mathrm{M}_{1}\right)$ is that of the $\mathrm{M}_{1} \mathrm{M}_{1} \mathrm{M}_{1}$ triad, and so on. In the present study, CB sequences were detected by UV spectroscopy after $\mathrm{HCl}$ elimination, and only the chlorine of the 1,4 structure was eliminated. Assuming the fraction of the 1,4 structure to be $k$ and the distribution of 1,4 and 3,4 structures as completely random (Bernoulli) as is the case in polyisoprene, ${ }^{19}$ we can derive the following equations:

$$
\begin{aligned}
& P_{2}\left(\mathrm{CB}_{1,4} \mathrm{CB}_{1,4}\right)=k^{2} P_{2}(\mathrm{CB} \mathrm{CB}) \\
& P_{3}\left(\mathrm{CB}_{1,4} \mathrm{CB}_{1,4} \mathrm{CB}_{1,4}\right)=k^{3} P_{3}(\mathrm{CB} \mathrm{CB} \mathrm{CB})(8) \\
& P_{3}\left(\mathrm{CB}_{1,4} \mathrm{CB}_{1,4} \mathrm{CB}_{1,4}\right) \\
& =2 k^{2}(1-k) P_{3}(\mathrm{CB} \text { CB CB }) \\
& P_{4}\left(\mathrm{CB}_{1,4} \mathrm{CB}_{1,4} \mathrm{CB}_{1,4} \mathrm{CB}_{1,4}\right) \\
& =k^{4} P_{4}(\mathrm{CB} \mathrm{CB} \text { CB CB }) \\
& P_{4}\left(\mathrm{CB}_{1,4} \mathrm{CB}_{1,4} \mathrm{CB}_{1,4} \mathrm{CB}_{3,4}\right) \\
& =2 k^{3}(1-k) P_{4}(\mathrm{CB} \text { CB CB CB }) \\
& P_{4}\left(\mathrm{CB}_{1,4} \mathrm{CB}_{1,4} \mathrm{CB}_{3,4} \mathrm{CB}_{3,4}\right) \\
& +P_{4}\left(\mathrm{CB}_{1,4} \mathrm{CB}_{1,4} \mathrm{CB}_{3,4} \mathrm{CB}_{1,4}\right) \\
& +P_{4}\left(\mathrm{CB}_{3,4} \mathrm{CB}_{1,2} \mathrm{CB}_{1,2} \mathrm{CB}_{3,4}\right) \\
& =\left\{3 k^{2}(1-k)^{2}+2 k^{3}(1-k)\right\} \\
& P_{4}(\mathrm{CB} \mathrm{CB} \mathrm{CB} \mathrm{CB})
\end{aligned}
$$

These notations can be understood without difficulty, but eq 12 may need annotation. The equation represents the total fractions of tetrads that contain the $\mathrm{CB}_{1,4} \mathrm{CB}_{1,4}$ diad, i.e., $\mathrm{CB}_{1,4} \mathrm{CB}_{1,4} \mathrm{CB}_{3,4} \mathrm{CB}_{3,4}, \mathrm{CB}_{3,4} \mathrm{CB}_{3,4}{ }^{-}$ $\mathrm{CB}_{1,4} \mathrm{CB}_{1,4}, \mathrm{CB}_{3,4} \mathrm{CB}_{1,4} \mathrm{CB}_{1,4} \mathrm{CB}_{3,4}, \mathrm{CB}_{1,4} \mathrm{CB}_{1,4}{ }^{-}$ $\mathrm{CB}_{3,4} \mathrm{CB}_{1,4}$, and $\mathrm{CB}_{1,4} \mathrm{CB}_{3,4} \mathrm{CB}_{1,4} \mathrm{CB}_{1,4}$. From these equations, the diad of 1,4-structure $\mathrm{CB}$ is represented by the sum of eq 7, 9, and 12 and the triad of 1,4-structure CB is the sum of eq 8 and 11 .

In the present treatment, the contribution from the sequences of $\mathrm{CB}$ larger than 4, for example, the pentad (CB CB CB CB $\mathrm{CB}$ ), was neglected, because the concentrations of such sequences were low in the $P(\mathrm{CB}-\mathrm{co}-\mathrm{St}) \mathrm{s}$ whose $\mathrm{CB}$ contents are not 
Microstructure of 1-Chlorobutadiene Copolymer with Styrene

Table V. Monomer sequence distribution in poly (CB-co-St)

\begin{tabular}{|c|c|c|c|c|}
\hline \multirow{3}{*}{ No. } & \multirow{3}{*}{$\begin{array}{c}\text { Absorbance } \\
\text { at } \\
304 \text { or } 364 \mathrm{~nm}\end{array}$} & \multicolumn{3}{|c|}{ Concentration of the diad or the triad $/ \mathrm{mol}^{\circ} \%$} \\
\hline & & \multirow[b]{2}{*}{ Observed $^{\mathrm{c}}$} & \multicolumn{2}{|c|}{ Calculated $^{\mathbf{d}}$} \\
\hline & & & $\begin{array}{l}\text { Without taking } \\
\text { microstructure } \\
\text { into account }\end{array}$ & $\begin{array}{c}\text { Taking } \\
\text { microstructure } \\
\text { into account }\end{array}$ \\
\hline \multicolumn{5}{|c|}{$\operatorname{diad}\left(\mathrm{CB}_{1,4} \mathrm{CB}_{1,4}\right), \lambda_{\text {max }}$ at $304 \mathrm{~nm}$} \\
\hline $11^{\mathrm{a}}$ & 0.13 & 0.20 & 0.42 & 0.16 \\
\hline $12^{\mathrm{b}}$ & 0.58 & 0.92 & 2.59 & 1.0 \\
\hline \multicolumn{5}{|c|}{$\operatorname{triad}\left(\mathrm{CB}_{1.4} \mathrm{CB}_{1.4} \mathrm{CB}_{1.4}\right), \lambda_{\max }$ at $364 \mathrm{~nm}$} \\
\hline $12^{\mathrm{b}}$ & 0.094 & 0.075 & 0.29 & 0.070 \\
\hline
\end{tabular}

high. The $\mathrm{HCl}$ elimation from the highCB-content copolymer was difficult to analyze owing to the formation of insoluble polymers.

Using $r_{\mathrm{CB}}=1.68$ and $r_{\mathrm{St}}=0.274,{ }^{2} \quad P_{2}(\mathrm{CB}$ $\mathrm{CB}), P_{2}(\mathrm{CB} \mathrm{CB} \mathrm{CB})$ and $P_{4}(\mathrm{CB} \mathrm{CB} \mathrm{CB} \mathrm{CB})$ were obtained by eq 4,5 , and 6 , respectively. From these values, the concentrations of the diad $\left(\mathrm{CB}_{1,4} \mathrm{CB}_{1,4}\right)$ and the triad $\left(\mathrm{CB}_{1,4}{ }^{-}\right.$ $\left.\mathrm{CB}_{1,4} \mathrm{CB}_{1,4}\right)$ were evaluated assuming $k=1.0$ (not taking microstructure into account) or $k=0.60 \quad$ (taking microstructure into account). The results are shown in Table $\mathrm{V}$ together with the observed values obtained from the observed absorbances in DMF and the reported $\varepsilon_{\max }{ }^{3}{ }^{17}$ for a conjugated tetraene $\left(\lambda_{\max } 304 \mathrm{~nm}, \varepsilon_{\max } 64000\right)$ and a hexane $\left(\lambda_{\max }{ }^{-}\right.$ $364 \mathrm{~nm}, \varepsilon_{\max } 138000$ ). These $\varepsilon_{\max }$ 's were not obtained in DMF, but it is known that the solvent effect on $\varepsilon_{\max }$ of a polyene is usually negligible. ${ }^{20}$

When the structures of $\mathrm{CB}$ units are taken into account, the theoretical concentrations of 1,4-CB sequences are in good agreement with those of the experimental. Winston and Wichacheewa ${ }^{3}$ reported only the ratios of absorbances or calculated concentrations of $\mathrm{CB}$ sequences, and the ratios may have not been sensitive enough to be influenced by neglect- ing the difference of $\varepsilon_{\max }$ and microstructures of the CB units.

The present along with earlier results on the copolymerization of $\mathrm{CB}$ and $\mathrm{St}^{1,2,4-7}$ show the terminal model (simple Markov theory) to be satisfactorily applicable to the bulk copolymerization of $\mathrm{CB}$ and $\mathrm{St}$ with AIBN, there to be cis-1,4, trans-1,4 and 3,4 structures in the $\mathrm{CB}$ units, the distribution of 1,4 and 3,4 structures to be completely random (Bernoullian), and the copolymer contains active chlorine ( $c a .60 \%$ of $\mathrm{CB}$ content) to be susceptible to nucleophilic reactions.

This information will be useful when attempting to prepare copolymers of preevaluated structures and using them as substrates in polymer reactions involving active chlorine.

\section{REFERENCES}

1. S. Kohjiya, K. Iwata, S. Yamashita, T. Miyamoto, and H. Inagaki, Polym. J., 15, 869 (1983).

2. S. Kohjiya, M. Kurokawa, K. Iwata, Y. Imoto, T. Enoki, and S. Yamashita, Polym. J., 17, 661 (1985).

3. A. Winston and P. Wichacheewa, Macromolecules, $\mathbf{6}$, 200 (1973).

4. S. Yamashita, M. Tamura, J. Terada, and S. Kohjiya, Rubber Chem. Technol., 50, 364 (1977).

5. S. Kohjiya, Y. Hongu, M. Tamura, and $\mathrm{S}$. Yamashita, Polym. Bull., 6, 209 (1981).

6. S. Yamashita, K. Sando, and S. Kojiya, J. Appl. 
Polym. Sci., 23, 1951, 1963 (1979).

7. S. Kohjiya, H. Takeuchi, K. Kawamoto, and S. Yamashita, Bull. Chem. Soc. Jpn., 54, 3245 (1981).

8. C. D. Gutsche and D. J. Pasto, "Fundamentals of Organic Chemistry," Prentice-Hall, Englewood Cliffs, N. J., 1975, Chapter 21.

9. J. D. Roberts and R. H. Mazur, J. Am. Chem. Soc., 73, 2509 (1951).

10. L. F. Hatch and S. S. Nesbitt, J. Am. Chem. Soc., 72, 727 (1950).

11. A. L. Henne and J. B. Hinkamp, J. Am. Chem. Soc., 67, 1197 (1945).

12. P. Radzitzki, M. C. Wilde, and G. Smets, J. Polym. Sci., 13, 477 (1954).

13. D. H. Lewis, R. C. Kneisel, and B. W. Ponder, Macromolecules, 6, 660 (1973).
14. J. C. Gressier, C. P. Pinazzi, and G. Levesque, Makromol. Chem., 176, 341 (1975).

15. Y. Bando and Y. Minoura, J. Polym. Sci. Polym. Chem. Ed., 14, 693 (1976).

16. S. Kohjiya, S. Fujiwara, K. Fujii, and S. Yamashita, Makromol. Chem., 183, 163 (1982).

17. F. Sondheimer, D. A. Ben-Efraim, and R. Wolousky, J. Am. Chem. Soc., 83, 1675 (1961).

18. K. Ito and Y. Yamashita, J. Polym. Sci., A, 3, 2165 (1965); C. W. Pyun, J. Polym. Sci., A-2, 8, 1111 (1970).

19. Y. Tanaka, H. Sato, and A. Ogura, J. Polym. Sci., Polym. Chem. Ed., 14, 73 (1976).

20. R. M. Silverstein and G. C. Bassler, "Spectroscopic Identification of Organic Compounds," John Wiley \& Sons, New York, N. Y., 1967, Chapter 5. 